IJ§ER

ISSN: 2149-5939
International Journal of Social Sciences and Education Research

Online, http://dergipark.gov.tr/ijsser

Volume: 1(1), 2015

\title{
Ekoturizmin yerel halk üzerindeki etkilerinin değerlendirilmesi
}

\author{
Evaluation of the impact of ecotourism on the local community
}

\begin{abstract}
Murad Alpaslan Kasalak ${ }^{1} \quad$ Zeki Akıncl²
Received Date: $01 / 01 / 2015$

Accepted Date: $01 / 02$ / 2015

$\ddot{O}_{z}$

Günümüzde en hızlı büyüyen sektörler arasında yer alan turizmin, sürdürülebilirliğini sağlamak ve dünya üzerinde farklı bölgelerde ortaya çıkan ekonomik kriz gibi unsurlardan en az şekilde etkilenmesini gerçekleştirmek için turizmi çeşitlendirmek, ülkeler açısından sadece kıyı turizmine önem vermek yerine, alternatif turizm yöntemleri geliştirmek bir zorunluluk haline gelmiştir. 1990'lı ylllardan sonra da alternatif turizm yöntemlerinden en ilgi çekenlerden birisi de ekoturizmdir. Ekoturizm, çevreyi koruyan ve yerel halka çeşitli imkânlar yaratan bir turizm çeşidi olarak birçok ülke açısından önemsenmektedir. Yerel halka sağladiğg imkânlar yönünden ekoturizm, çevresel, ekonomik ve sosyo-kültürel etkilere sebep olmaktadır. Çalışmamızda ekoturizmin yerel halk üzerinde oluşturduğu, çevresel, ekonomik ve sosyo-kültürel etkilerinin olumlu ve olumsuz anlamda neler olduğu ve yerel halka nasl firsatlar yarattı̆̆ değerlendirilmiştir. Ekoturizmin olumlu etkileri kapsamında yerel halka yönelik yarattı̆̆ firsatlar hakkında öneriler sunulmuştur.
\end{abstract}

Anahtar sözcükler: Ekoturizm, yerel halk, ekonomik, çevresel, sosyo-kültürel etki

\begin{abstract}
Today, tourism is among the fastest-growing sector and to ensure the sustainability of the economic crisis that emerged in different regions of the world to affect the way elements such as to perform at least diversify tourism, instead of only giving importance to tourism in terms of coastal countries, and to develop methods of alternative tourism has become a necessity. Then the 1990s alternative tourism ecotourism is one of the methods of the people who are most interest to you. Ecotourism is tourism that conserves the environment and creates various opportunities for local people in many countries are regarded as a sort. Facilities provided by local people in terms of ecotourism, environmental, economic and socio-cultural causes effects. In our study, ecotourism to the local community that might pose environmental, economic and socio-cultural impact of what is happening in positive and negative sense has created opportunities for local people and how they were evaluated. The positive effects of ecotourism has created opportunities for local people about the scope of suggestions are presented.
\end{abstract}

Keywords: Ecotourism, local community, economic, environmental, socio-cultural impact

\section{Giriş}

Günümüzde turizm, başta gelişmekte olan ülkeler olmak üzere birçok ülke açısından ekonomilerinin destekleyen önemli bir sektör olarak yer almaktadır. Bu sektör aynı zamanda ülkelerde yer alan bölgesel gelişmişlik farklarını ortadan kaldırmaya yönelikte bir araç olarak kullanılabilmektedir. Özellikle Alternatif turizm çeşitlerinden biri olan ve doksanlı yıllarda daha da fazla ilgi

\footnotetext{
${ }^{1}$ Assist. Prof. Dr., Akdeniz University, Tourism Faculty ANTALYA/TURKEY, muradkasalak@akdeniz.edu.tr ${ }^{2}$ Assist. Prof. Dr., Akdeniz University, Tourism Faculty ANTALYA/TURKEY, zakinci@akdeniz.edu.tr
} 
Kasalak, M.A., Akınc1, Z. (2015). Evaluation of the impact of ecotourism on the local community. International Journal of Social Sciences and Education Research, 1 (1), 189-196.

çeken sürdürülebilir turizm olgusunun bir meyvesi olarak ortaya çıkan ekoturizm, birçok ülkede yerel halka sosyo-ekonomik katkı sağlayan bir faaliyet alanı olarak karşımıza çıkmaktadır.

Ekoturizm, ilkeleri açısından yerel halkı ve doğayı önemseyen bir turizm çeşididir. Fakat bazı ülkelerde elde edilen ekonomik değer üzerinden ekoturizmin ele alınması ve iyi planlanmaması yerel halk ve çevre üzerinde olumlu ya da olumsuz etkilere yol açabilmektedir.

\section{Ekoturizmin etkileri}

Ekoturizm çevreyi koruyan ve yerel halkın refahını arttıran doğal alanlara seyahat olarak tarif edilmiştir. Ekoturizm bir kırsal turizm türü olarak ele alınmaktadır. Ekoturizm, doğa temelli turizm, yumuşak turizm, özel ilgi turizmi, yeşil turizm, sorumlu turizm, alternatif turizm, kültürel turizm, inceleme turizmi, macera turizmi gibi birçok farklı isimle de ifade edilmiştir. Ekoturizm, doğa güzelliği, jeoloji, fauna ve belirli bir alanın yerel kültürü ve florasına odaklanmaktadır. Dünya'da benzersiz veya oldukça doğal bozulmamış alanlar ve kültürel özellikleri, sürdürülebilir bir şekilde korumak ve aynı zamanda bu destinasyonlardan gelir etmek toplumun ilgisini çekmektedir. Bir ekoturist "ecotrip" yâda "ecotour" seçtiğinde doğal kültürel özellikleri önemseyen koruma bilgi ve anlayışı kazanır. Turist sadece doğrudan korunmasına katkı değil, aynı zamanda ekonomik katkısı ve varlığının sağlanması için teşvik sağlar. Turizm kurumları ve devlet yönetimi politikalarını teşvik ve yerel işletmelerin desteği ile korunmasını dengelemek amacıyla uzmanlık sağlayarak korunmasına katkıda bulunur (Masberg ve Morales,1999:289).

Bir kırsal kalkınma aracı olarak ele alınmasıyla birlikte, yaşanan deneyimler turizmin olumlu sonuçları ile birlikte olumsuz sonuçlarının da olabileceğini göstermiştir. Kırsal turizm sürdürülebilir turizm ile en uyumlu turizm çeşitlerinden biri olarak algılanmasına rağmen doğal, kültürel ve sosyal kaynakların kullanımı, yaratılan kaynakların ve ekonomik gelirin paylaşımı ile birlikte yerel halkın yerinden olması gibi konularda çıkar çatışmalarına neden olabilmektedir (Ertuna, 2012:60). Başka bir ifade ile ekoturizm faaliyetleri iyi organize edilmediği takdirde, kitle turizmi gibi çevrenin tahrip olmasına ve maddi-manevi kültür unsurlarının bozulmasına neden olabilmektedir. Fakat doğal ve kültürel varlıkların korunması yönündeki bilinci artırma ve ev sahibi toplum için alternatif is ve gelir olanakları yaratma temeline dayalı olan ekoturizm, fiziksel, ekonomik ve sosyo-kültürel çevre üzerinde en düşük olumsuz etkiye sahip turizm çeşidi olarak karsımıza çıkmaktadır (Yılmaz, 2008:77).

Bu nedenle ekoturizmin olumlu ve olumsuz etkilerini üç ana başlık olarak ekonomi, çevre ve sosyo-kültürel yapıya etkileri şeklinde incelemek uygun olacaktır.

\subsection{Ekoturizmin ekonomik etkileri}

Dünyanın en büyük endüstrisi olarak yerini alan turizm için ekoturizm, yıllık büyüme oranının \% 10'dan \% 30'a çıkacağı tahmini ile en hızlı büyüyen sektördür. Ekoturizm, doğal güzelliğe sahip ve kültürel açıdan eşsiz olan alanlar için gelecek vadeden ekonomik gelişme firsatı sağlar (Kuter ve Ünal, 2009:152). Yerel kaynaklara da gelir sağlayan bir unsurdur. Örneğin, Çin'de ekoturizm mülkiyetinden elde edilen parasal gelirler, önce yerel hükümete sonra merkezi hükümete aktarılır (Cheng ve Wang, 2010:128). Fiji'de ekoturizmin yoğun olarak gerçekleştirildiği iki köy üzerinde yapılan bir araştırma, köyde ekoturizmin geliştirilmesi sonrası eğitim ve gelir düzeyinde önemli artışlar meydana geldiğini göstermiştir.

Ekoturizmin yaratacağı olumlu ekonomik etkiler şunlardır: 
Kasalak, M.A., Akıncı, Z. (2015). Ekoturizmin yerel halk üzerindeki etkilerinin değerlendirilmesi. International Journal of Social Sciences and Education Research, 1 (1), 189-196.

- Turizmle ilgili konaklama tesisleri, restoranlar, hediyelik eşya satan dükkânlar, seyahat hizmetleri gibi yöredeki diğer ekonomik faaliyetlerin gelişmesine katkıda bulunur (Örneğin, Brezilya'da sadece el yapımı mendil satısından 1 kişi 1 yılda ortalama 2336 Amerikan doları kazanmaktadır. Yine, Kosta Rika'da 1995 yılında çiftçilerin kazandığı para miktarının kişi basına 12 bin dolar olduğu tespit edilmiştir (Yılmaz, 2008: 78)),

- Yerel ekonomide çeşitlilik yaratarak, özellikle tarıma dayalı aktivitelerle yeterli istihdam sağlayamayan yerel halka doğrudan veya dolaylı yeni iş olanakları yaratır,

- Turistlerden elde edilecek gelirle destinasyona ve özellikle yerel halka doğrudan bir ekonomik katkı sağlar,

- Yöreye has el sanatları ve yiyecekler gibi yerel ürünlere olan talebi arttırır. Yerel halka kültürel öğeleri taşıyan el sanatları ürünlerini satma firsatı yaratarak, sağladığı ekonomik katkı ile aynı zamanda yerel kültürün korunması için bir araç olabilir,

- Eğer iyi yönetilirse, koruma alanları ve park yöneticileri için kendini finanse edebilecek bir sistemi oluşturabilir. Böylece doğal alanların korunmasında bir araç olarak önemli bir fonksiyonu üstlenebilir (Demir ve Çevirgen, 2006: 70-71).

Ekoturizmin ekonomiye olumlu etkileri yanında olumsuz ya da fazla etki göstermeyen bir etkisi olduğuna yönelik görüşlerde söz konusudur. Gaul (2003)'e göre ekoturizmin olumsuz ekonomik etkilerinden biri yerel enflasyona sebep olması (iş gücüne ödenen ücretler ve yerelde üretilen mallarda artış)'dır. Uluslararası Turizm Derneği (TIES)'ne göre ekoturizmin ortaya çıkarabileceği olumsuz ekonomik sonuçlar ise şunlardır;

- Yerel toplumun ekoturizme yönelik beklentilerinin sınırlı olması, onların doğal ve kültürel kaynaklarını koruma konusundaki isteklerini azaltmak gibi bir sonucu da beraberinde getirmektedir,

- Yöredeki oteller ve benzeri tesislerin su ve enerji gibi kaynakları aşırı tüketmeleri, bölgedeki fiyatları arttırmakta, elektrik ve su kesintilerine neden olabilmektedir (Kuter ve Ünal, 2009:153).

\subsection{Ekoturizmin çevresel etkileri}

Ekoturizm, düzensiz rekreasyon, aşırı binalaşma, aşırı kalabalık, yaban hayatına yönelik kargaşa ve araç kullanımı gibi durumlara hassas olmayı içerir. Ekoturizm bu etkileri dikkate alır, çünkü ekoturizm nispeten bozulmamış doğal ortamlara yeni ziyaretçileri çekmeye dayanan bir kavramdır. Ekoturistler genellikle uygun mevsimlerde özel alanları ziyaret ederek yerinde ekoturizm gerçekleştirirler (Ayotte, 2009:20).

Ekoturizme karşı artan ilgi beraberinde birçok olumlu sonuç da getirmiştir. Dünyanın birçok bölgesinde hükümetler değerli doğa alanlarını doğal park ya da koruma alanı haline getirmekte, bunları tarım, kereste ticareti ya da madencilik gibi çevreye zarar veren faaliyetlere karşı koruma altına almaktadır. Ekoturizmdeki en önemli artışlar koruma alanlarının en fazla olduğu yerlerde gerçekleşmiştir. 1997'de Güney Afrika'yı ziyaret eden 6 milyon turistin yaklaşık \%60’ı bir ulusal park ya da doğa rezervine (koruma altına alınmış alana) gitmiştir. Bazı eko tatil köyleri çevreye karşı önemli taahhütlerde bulunmakta, turistlerin yarattı̆ğ etkiyi ve kendi ekolojik ve toplumsal izlerini ayrıntılı bir şekilde izlemektedirler. Lüksten uzak kulübelerde enerji kaynağı olarak elektrik ya da odun değil propan, gaz yağı, güneş ya da rüzgâr enerjisi kullanılmakta, ev içinde su 
Kasalak, M.A., Akıncı, Z. (2015). Evaluation of the impact of ecotourism on the local community. International Journal of Social Sciences and Education Research, 1 (1), 189-196.

tesisatı bulunmamakta ve mümkün olduğu kadar az atık üretilmektedir. Kosta Rika'nın en gözde ulusal parklarından Manuel Antonio'daki Si Como No tatil köyünde güneş enerjisi kullanılmakta, ulaşım araba ya da yürüyüş yolu yerine hava köprüleriyle sağlanmakta, erozyonu engelleme arac1lı̆̆ı ile bölgeye özgü bitkiler yetiştirilmektedir (Kuter ve Ünal, 2009:151). Ekoturizm özellikle gelişmekte olan ülkelerde çevresel kaynakların ve biyolojik çeşitliliğin korunmasının desteklenmesinde önemli bir araç olarak görülmektedir. Örneğin, 1990’ların ortalarından itibaren pek çok Afrika ülkesinde ekoturizme yönelik 105 proje için yaklaşık 2 milyon Amerikan Doları harcama yapılırken, 1988-2003 yılları arasında "Afrika'da Korunmuş Alanları" destekleyen 55 projeden 32'si Dünya Bankası tarafindan finanse edilmiştir. Bugün ekoturizm, hassas ekosistemlerin ve doğal alanların sadece korunması değil, aynı zamanda iyileştirilmesine katkı sağlaması bakımından geliştirilebilecek en iyi turizm sekli olarak görülmektedir (Y1lmaz, 2008:80).

Ekoturizmin başlıca amacı çevreyi koruma ve çevreye saygı olsa da doğru yönetilmeyen ve uygulanmayan ekoturizm faaliyetleri çevresel yönden bazı olumsuz sonuçlara sebep olabilmektedir.

Yapılan çeşitli çalışmalarda, ekoturizmin olumsuz çevresel etkileri şu örneklerle ortaya konulmaya çalışılmıştır:

- Kenya'da Amboseli National Park'ta safari faaliyetleri yaban hayatını olumsuz yönde etkilemiş ve bölgede çita nüfusu yok olma eşiğine gelmiştir,

- $\quad$ ABD'de bulunan Yellowstone Milli Parkı'nda turistlerin bıraktıkları atıklar yüzünden, bölgede yaşayan ayılar zamanla ölmeye başlamışlardır,

- Kaliforniya'da Monarchy kelebeklerinin kışlama bölgesinde, ekoturizme dayalı faaliyetlerin aşırı büyümesi sonucu, kelebeklerin kışlama ve üreme alanları yok olmuştur,

- Alaska'da kahverengi ayıların ekoturizm faaliyetlerinden olumsuz şekilde etkilendiği kanıtlanmıştır,

- Guatemala'da Tikal Milli Parkı'nda gerçekleşen ekoturizm faaliyetleri de birçok hayvanın yaşamını olumsuz yönde etkilemiştir,

- Himalayalar'da gerçekleşen ekoturizm faaliyetlerinin artmasıyla bölgede çöp sorunu ortaya çıkmış, bölgeye büyük konaklama işletmelerinin yapılması ile ise su kaynakları kirlenmiştir,

- Meksika Mangrov ormanları, tuz bataklıkları ve kıyılarda yaban hayatına kucak açan ve mercan kayalıklarını koruyan sulak alanlar temizlenip doldurulmuş, bunların üzerine tatil köyleri, iskele ve marinalar yapılmıştır,

- Nepal'de bulunan Sagarmantha Milli Parkı'nda ekoturistlerin bıraktıkları çöpler yığın haline gelmiştir ve milli parkta ormansızlaşma görülmüştür (Şen, 2010:119-120).

- Nepal'de Arnapurna Koruma alanı, en popüler trekking destinasyonlarından birisidir. Burada da çeşitli sorunlar ortaya çıkmaktadır. Çok fazla yakacak odun ve 700'den fazla konaklama birimi yapımı için kereste ünlü Rhodendron (orman güllerini) ormanı dahil yaban hayatı habitatını değiştirmiş̧ir (Altan, 2006:70).

- Brezilya'da ekoturistlerin fotoğraf çekmeleri ve Belize sahillerinde sürat motoru kullanmaları tropikal kuşların bu bölgeleri terk etmelerine neden olmuştur, 
Kasalak, M.A., Akıncı, Z. (2015). Ekoturizmin yerel halk üzerindeki etkilerinin değerlendirilmesi. International Journal of Social Sciences and Education Research, 1 (1), 189-196.

- Ekoturizmin çevreyi olumsuz yönde etkilemesi ile ilgili olarak verilebilecek en çarpıcı örneklerden biri de, Antartika'da meydana gelen bir çevre felaketidir. Antartika'nın çevresinde 300 kadar ekoturisti taşıyan bir gemi 250.000 galon (yaklaşık 947.000 lt) yağını kazara 20.000 penguenin yuva yaptı̆̆ bir bölgede denizine dökmüştür (Yılmaz, 2008: 81).

\subsection{Ekoturizmin sosyo-kültürel yaplya etkileri}

Turizm, ekonomik ve çevresel pek çok etki göstermektedir. Ancak turizmin gösterdiği etkiler sadece ekonomi ve çevre boyutuyla sınırlı değildir. Ekonomik getirilerinin yanı sıra, turizmin doğal çevreye ve kültürel yapıya da olumlu katkılarda bulunduğu tartışılmakla beraber, turizmin eskiden öngörüldüğü kadar zararsız ve maliyetsiz bir ekonomik seçenek olmadığı giderek savunulan görüşler arasındadır. Gelir düzeyleri ve sosyal değerleri arasında farklar bulunan değişik toplumların çekim yerlerinde bir araya gelmesiyle kültürel etkileşim sürecinin başladığ 1 ve bunun bir kültürün diğerinin etkisi altında kalarak kısmen ya da tamamen değişime uğrayabileceği değişik araştırmacılarca vurgulanmaktadır.

Pek çok araştırmacı turizmin toplumu çok yönlü olarak etkilediğini belirtmişler ve bu etkilerin birbirinden ayrılmasının çoğu kez zor olduğunu ifade etmişlerdir. Örneğin; Haley v.d. (2005) araştırmalarında, turizmin nicel etkilerinin yanında elle tutulamayan, öznel pek çok etkilerinin de mevcut olduğunu ifade etmişlerdir (Özmen, 2007:18).

Ahipaşalığlu'na göre; değer sistemlerinde, kişisel davranışlarda, aile ilişkilerinde, ortak yaşam tarzlarında, güvenlik düzeyinde, ahlak kurallarında, geleneksel törenlerde ve toplum örgütlenmesinde yarattığı değişimler turizmin sosyo-kültürel etkilerdir. Kırsal turizm de bireyler ve toplum üzerinde çeşitli sosyo-kültürel etkiler yaratmaktadır (Yeniçare, 2012:4).

Farklı kültürler ve farklı ırklardan insanları bir araya getiren ve yerel toplum saygısını artıran ekoturizmden elde edilen gelir yerel halka kazanç sağlamakta ve iş bulmak için yapılan göçleri de kontrol altında tutmaktadır. Böylece yerel bilgiler de toplum içinde kalarak devamlılığ sağlanmaktadır (Kuter ve Ünal, 2009:153).

Ekoturizm eğilimini destekleyenler onun sosyo-ekonomik değerini vurgulamakta ve aşağıda belirtilen olası bazı sosyo-ekonomik faydalar içerdiğini savunmaktadırlar:

- Ulaşım ve iletişim sistemleri altyapılarının gelişmesi sonucunda yerel halka hizmet etmiş olur,

- Ekoturizm yerel ürünlere olan talebi artırır,

- Kenarda kalmış tarıma elverişli geniş toprakların verimli kullanılmasını özendirerek, bu yerlerin doğal bitki örtüsü ile kalmasına olanak verir,

- Uygun yönetildiği takdirde, özellikle ekoturizm faaliyetlerinin yapıldığı milli park v.b yerlerin yetkililerine, bu yerlerin kendi finansmanını sağlayan bir mekanizma olarak doğal mirasın korunmasına hizmet eden bir araç olmuş olur,

- Ekoturizm, ekonomik destek sağlayarak, yerel kültürlerin korunması sağlar,

- Turizm gibi, kültürler arası anlayış ve küresel iletişimi kolaylaştırıcıdır (Khabbazi ve Yazgan, 2012:8). 
Kasalak, M.A., Akıncı, Z. (2015). Evaluation of the impact of ecotourism on the local community. International Journal of Social Sciences and Education Research, 1 (1), 189-196.

Ekoturizmin insanlar arasında kültürel iletişimi sağlaması ve diğer olumlu etkileri dışında yöre halkı üzerinde bazı olumsuz etkilere de yol açmaktadır. Turizmin geliştirilmesi amacıyla yerel ve doğal alanlarda önemli değiş̧iklikler yapılmaktadır. Yerel topluluklarda, insanlar topraklarından ve yüzlerce yıldır kullandıkları deniz ve doğadan mahrum bırakılmaktadır. Geleneksel üretim faaliyetleri ortadan kaldırılmakta onun yerine mevsimlik faaliyete dayanan bir kültür ve ticari bir ilişki biçimi kurulmaktadır. Böylece, bir kültür tümü ile ortadan kaldırılarak turizm endüstrilerine fonksiyonel bir yapı kurulmaktadır. Özellikle de yerel topluma ekonomik firsatlar verilmediği zaman, turizmde yer almak istiyorlar $\mathrm{m} 1$ istemiyorlar $\mathrm{m} 1$ ve nasıl yer almak istiyorlar gibi sorular cevaplanmadığı sürece sosyal etkiler daha da artacaktır. Ringer'e göre planlama yapanlar ziyaret edilen yerlerde yaşayan toplumun ilgilerini ve duyarlılıklarının dikkate almadan planlama yapmaktadır (Altan,2006:70-71).

Ekoturistlerin en uzak kırsal alanlara bile girebileceği göz önüne alınırsa, bu bölgedeki doğal yaşamın bozulabileceğinden ve zamanla küreselleşme çarkının bu bölgelerde de hissedilmeye başlanmasıyla bölgede yaşayan yerel halkın kültüründe, geleneklerinde olumsuz yönde değişimler olabileceğinden söz edilebilir.

SSCI tarafından taranan 10 dergide, ekoturizmin etkileri ile ilgili yayınlanan 62 çalışma Özkök ve Çoban (2009: 599) tarafından incelenmiş ve yayınlanan bu çalışmaların 25'inin ekoturizmin kültürel etkileri ile ilgi sonuçları bulunmuştur. 25 çalışmanın 10'unda bölgede yerel halkın geleneksel yaşamının devam ettiği, bu sonuca bağlı olarak ekoturizmin yerel kültüre önem veren ve yerel kültürü destekleyen bir turizm yaklaşımı olduğu söylenmiş̧ir. 25 çalışmanın 15 'i ise ekoturizm faaliyetlerinin bölgede kültürel değişim yarattı̆̆ını ortaya koymaktadır (Şen,2010:126).

Doğa turizmi yerel halk tarafından, özellikle turistlerin en sık gittikleri gelişmekte olan ülkelerin yerel halkı tarafından bazen pek hoş karşılanmaz. Çünkü gelen turist zenginken, yerliler çok fakirdir. Örneğin Nepal'deki Chitwan Milli Parkı'nı ziyaret eden turistlerin çoğunun Nepal'li olmaması ve yabancıların yerel sorunlarla ilgilenmemesi bu hoşnutsuzlukları arttırmaktadır. Parktaki yaban hayatı (gergedanlar yılda 3-5, kaplanlar yılda 1 kişi) her yıl yerlileri öldürmekte ve tarım ürünlerine zarar vermektedir. Ayrıca yerel fiyatların artışı ve yerlilerin parkta oldukça sınırlı çalışma imkânları milli parka karsı hoşnutsuzluk yaratmaktadır. Benzer şekilde Hindistan'daki Dubhwa Milli Parkı'nda 4 yılda 93 kişi kaplanlar tarafindan öldürülmüştür (Erdoğan, 2003:159160).

\section{Sonuç ve öneri}

Ekoturizm, yerel halka ekonomik fayda sağlayan, kırsal alanda yaşayan kişilerin bulundukları yerlerdeki kültürel değerlere sahip çıkmalarını ve önemsemelerine yol açan ve aynı zamanda ekoturistler ile etkileşimde bulunulması suretiyle kültürler arası bir köprü oluşturan doğa temelli ideal bir turizm türü olarak görülmektedir. Bu turizm türünün en iyi şekilde planlanması olumsuz ekonomik, çevresel ve sosyo-kültürel etkileri azaltacaktır.

O nedenle ülkelerin ekoturizm faaliyetlerini; yerel halkında görüşlerini alarak iyi planlanmış ve organize etmiş şekilde gerçekleştirmeleri gerekmektedir. Böylelikle doğayı korumayı ve yerel halka ekonomik katkı sağlamayı kendine amaç edinmiş bu sürdürülebilir turizm türünün devamlılığı sağlanacaktır. 
Kasalak, M.A., Akıncı, Z. (2015). Ekoturizmin yerel halk üzerindeki etkilerinin değerlendirilmesi. International Journal of Social Sciences and Education Research, 1 (1), 189-196.

\section{Kaynakça}

Altan, Ş. (2006). Türkiye'de Ekoturizm Uygulamaları ve Ekonomiye Katkıları. Niğde: Yüksek Lisans Tezi, Niğde Üniversitesi Sosyal Bilimler Enstitüsü.

Ayotte, A. L. (2009). Ecotourism as a Form Of Sustainable Development In South Africa. Canada: Quenn's University the Degree of Masters of Environmental Studies.

Cheng, L. ve Wang, T. (2010). Analysis On The Future Policy Tendency Of Ecotourism Management Based On The Appropriation Of Benefits İn Western China. Society And Natural Resources, 23, 128145 .

Demir, C. ve Çevirgen, A. (2006). Ekoturizm Yönetimi. İzmir: Nobel Yayın Dağıtım.

Erdoğan, N. (2003). Çevre ve (Eko)Turizm. Ankara: Erk Genel Yayın Dağıtım.

Ertuna, B., Güney, S., Güven, Ö. ve Aydemir, N. (2012). Yerel Halkın Kırsal Turizm Gelişimine Katılma İsteğini Etkileyen Unsurlar: Kastamonu Örneği. Uluslararası Sosyal ve Ekonomik Bilimler Dergisi, 2(2), 59-66.

Khabbazi, A. P. ve Yazgan, M. E. (2012). Kirsal Peysaj ve Ekoturizm. Uluslararası Sosyal ve Ekonomik Bilimler Dergisi,2(2), 5-9.

Kuter, N. ve Ünal, H. E. (2009). Sürdürebilirlik Kapsamında Ekoturizmin Çevresel, Ekonomik ve SosyoKültürel Etkileri. Kastamonu Üniversitesi Orman Fakültesi Dergisi,9(2), 146-156.

Masberg, B.A. ve Morales, N. (1999). A Case Analysis Of Strategies İn Ecotourism Development, Aquatic Ecosystem Health and Management Society, 2, 289-300.

Özmen, M. (2007). Turizmin Sosyo-Kültürel Etkileri: Akçakoca Örneği. Bolu: Yüksek Lisans Tezi, Abant İzzet Baysal Üniversitesi Sosyal Bilimler Enstitüsü.

Şen, D. S. (2010). Turizmin Çevresel Etkileri ve Bir Çözüm Olarak Ekoturizm. Mersin: Yüksek Lisans Tezi, Mersin Üniversitesi Sosyal Bilimler Enstitüsü.

Yeniçare, E. (2012). Kırsal Turizm Nedir ve Örnekler Üzerinde İrdelenmesi. http://www.belgeler.com/blg/2kag/kirsal-turizm-peyzaj Erişim tarihi 11.10.2015.

Yılmaz, H. (2008). Turizm Çeşitlendirilmesi Kapsamında Ekoturizmin Ürünü Olarak Tatil Çiftlikleri: Türkiye'deki Tatil Çiftliklerine Yönelik Swot Analizi. Afyon: Doktora Tezi, Afyon Kocatepe Üniversitesi Sosyal Bilimler Enstitüsü. 
Kasalak, M.A., Akınc1, Z. (2015). Evaluation of the impact of ecotourism on the local community. International Journal of Social Sciences and Education Research, 1 (1), 189-196.

\section{Extended abstract in English}

Instead of giving importance only coastal tourism for the countries It has become necessity to diversify alternative methods of tourism which is the fastest growing sector among others for realising the minimum impact of the factors such as the economic crisis in different parts of the world. After 1990, one of the most interesting alternative tourism method is ecotourism. Ecotourism is defined as travel which protects the environment and improves the welfare of local people. Ecotourism is considered as a kind of rural tourism. Ecotourism has been expressed by many different names such as nature-based tourism, soft tourism, special interest tourism, green tourism, responsible tourism, alternative tourism, cultural tourism, adventure tourism. Ecotourism focuses on natural beauty, geology, fauna and flora of the local culture of the special area.

Ecotourism is considered important in terms of protecting the environment and local communities in many countries as a kind of tourism that creates various opportunities. Considered together with the rural development tool, experience has shown that there may be negative results with positive results in tourism. Rural tourism, although perceived as one of the most compatible forms of tourism with sustainable tourism which result conflicts in the use of cultural natural and social resources, the displaced of local people with shairing of created rescources and economic income. In other words if Ecotourism activities are not well organized, it can lead to degradation of material and spiritual culture elements and the destruction of the environment like mass tourism. But the natural and cultural assets to increase awareness for the protection and host ecotourism is based on the creation of alternative employment and income opportunities for the community, physical, economic and socio-has the lowest negative impact on the cultural environment in the types of tourism emerges.

Ecotourism provides economic development opportunity for the areas which has natural beauty and cultural uniqueness. For example, monetary income derived from ownership of ecotourism in China, transferred before local government then central government. A study on ecotourism in Fiji two villages carried out intensively, after the development of the village and ecotourism education level showed significant increases in revenue occurred. Ecotourism contains sensitive in the situations of irregular recreation, extreme building overcrowding on wildlife. Tourism shows much economic and environmental impact. But the effects of tourism are not limited to the economy and environmental dimensions. Besides the economic benefits and positive contribution it is suggested that tourism is not harmless and economical option as previously anticipated. it is highlighted by different researchers Income levels and social values between the start of the acculturation process with a combination of gravity of the various communities who are the differences remain partially or may be subject to completely change under the influence of the other's culture. According to Ahipaşaoğlu; their value systems, personal behavior, family relationships, in public life, the security level of ethics, traditional ceremonies and socio-cultural organization of society changes is effects of tourism. Income derived from ecotourism which brings people together from different cultures and different races providing profit for local people and keep migration under the control for work. Thus local information also provides continuity bu staying in local communities. In terms of the opportunities provided by the local community ecotourism causes environmental, economic and socio-cultural impact. In our study it si evaluated that how ecotourism impacts on local people from positive and negative aspects and how creates opportunities for local people. The context of the positive effects of the ecotourism about creating opportunities for the local population were presented. 